\title{
Anti-cancer effect of ursolic acid activates apoptosis through ROCK/PTEN mediated mitochondrial translocation of cofilin-1 in prostate cancer
}

\author{
WEN-TAO GAI ${ }^{1,2}$, DA-PENG YU ${ }^{3}$, XIN-SHENG WANG $^{1}$ and PEI-TAO WANG ${ }^{1}$ \\ ${ }^{1}$ Department of Urology, The Affiliated Hospital of Qingdao University, Qingdao, Shandong 266003; \\ ${ }^{2}$ Department of Urology, Yantai Municipal Laiyang Central Hospital, Laiyang, Shandong 265200; \\ ${ }^{3}$ Department of Urology, Jining No. 1 People's Hospital, Jining, Shandong 272000, P.R. China
}

Received May 8, 2015; Accepted May 13, 2016

DOI: 10.3892/ol.2016.5015

\begin{abstract}
Ursolic acid is a type of pentacyclic triterpene compound with multiple pharmacological activities including cancer resistance, protection from liver injury, antisepsis, anti-inflammation and antiviral activity. The present study aimed to investigate the anticancer effect of ursolic acid. Ursolic acid activates cell apoptosis and its pro-apoptotic mechanism remains to be fully elucidated. Cell Counting kit- 8 assays, flow cytometric analysis and analysis of caspase- 3 and caspase- 9 activity were used to estimate the anticancer effect of ursolic acid on DU145 prostate cancer cells. The protein expression of cytochrome $c$, rho-associated protein kinase (ROCK), phosphatase and tensin homolog (PTEN) and cofilin-1 were examined using western blot analysis. In the present study, ursolic acid significantly suppressed cell growth and induced apoptosis, as well as increasing caspase- 3 and caspase- 9 activities of DU145 cells. Furthermore, cytoplasmic and mitochondrial cytochrome $c$ protein expression was significantly activated and suppressed, respectively, by ursolic acid. Ursolic acid significantly suppressed the ROCK/PTEN signaling pathway and inhibited cofilin-1 protein expression in DU145 cells. The results of the present study indicate that the anticancer effect of ursolic acid activates cell apoptosis through ROCK/PTEN mediated mitochondrial translocation of cofilin-1 in prostate cancer.
\end{abstract}

Correspondence to: Mr. Xin-Sheng Wang, Department of Urology, The Affiliated Hospital of Qingdao University, 16 Jiangsu Road, Qingdao, Shandong 266003, P.R. China

E-mail:wang82911616@163.com

Key words: ursolic acid, prostate cancer, cytochrome $c$, rho-associated protein kinase/phosphatase and tensin homolog, cofilin-1

\section{Introduction}

Prostate carcinoma is common among elderly men and has a high incidence in Europe and America, being second in terms of cancer-associated mortality (1). In East Asia, the morbidity of prostate cancer is relatively low but has demonstrated a rising trend due to the aging population, dietary structure alterations and improvements in diagnosis (2). Prostate carcinoma is currently the focus of much research attention, and if identified early and treated correctly patient quality of life and treatment efficacy will be high (3).

According to previous studies, the use of Chinese herbs to treat tumors is achieving increasing recognition (4-6). Previous studies have reported that Traditional Chinese Medicine (TCM) has effects on androgen-dependent and -independent prostate carcinoma (7-9). At present, there are seldom resources of TCM for the treatment of prostate carcinoma and the results of clinical and experimental studies are indispensable for further data regarding TCM therapy for the treatment of this disease (10).

The natural compounds extracted by TCM have been widely used to treat a number of diseases (11). Researchers have studied structural modification and artificial synthesis using the natural structure as a template to investigate the structure of these compounds (12). At present, numerous natural compounds utilized as medicines have demonstrated multiple chemical properties (13). These natural medicines are a homologous series of natural products composed from important sources of natural compounds whose structures are combined together for modern drug development (14). For example, pentacyclic triterpene compounds are a type of plant secondary metabolite with clinical antitumor research and development value, and the most in-depth studies concerning these compounds have been performed on lupane, oleanolic acid and ursolic acid (15). Ursolic acid is pentacyclic triterpene compound that is widespread in nature, and is present in the leaves and fruits of Ericaceae bearberry, leaves of Scrophulariaceae paulownia tomentosa and Oleaceae privet (16). Ursolic acid has extensive biological activity, including cancer resistance, protection from liver injury, antisepsis, anti-inflammation and antiviral activity $(13,17)$. 
It has previously been reported that only dephosphorylated cofilin can translocate into mitochondria to induce apoptosis, while phosphorylation inhibits mitochondrial translocation of cofilin and, thus, apoptosis (18). Phosphatase and tensin homolog (PTEN) is the substrate of rho-associated protein kinase 1 (ROCK1) kinase, which is involved in regulating cell survival and cell death. Substantial evidence indicates that the activation of Ras homolog gene family, member A (RhoA)/ROCK1 can increase PTEN activity, thus, inhibiting the activation of Akt. Furthermore, ROCK1 can lead to the dephosphorylation of cofilin by activating protein phosphatase $1 / 2 \mathrm{~A}$, inducing cofilin mitochondrial translocation and leading to mitochondrial damage (19). In addition, ROCK1 can induce the translocation of dynamin-related protein 1 (Drp1) into mitochondria by regulating the phosphorylation state of Drp1, resulting in remodelling of the morphology of mitochondria (20).

In the present study, evidence was provided that indicates that the anticancer effect of ursolic acid may activate apoptosis of prostate cancer cells via ROCK/PTEN-mediated mitochondrial translocation of cofilin-1.

\section{Materials and methods}

Reagents. RPMI-1640 medium and fetal bovine serum were purchased from Gibco (Thermo Fisher Scientific, Inc., Waltham, MA, USA). Ursolic acid (with a purity of 90\%) was purchased from Sigma-Aldrich (St. Louis, MO, USA) and its chemical structure is indicated in Fig. 1. Cell Counting kit (CCK)-8 and bicinchoninic acid protein assays were purchased from Sangon Biotech Co., Ltd. (Shanghai, China). Annexin V-fluorescein isothiocyanate (FITC)/propidium iodide (PI) Apoptosis Detection kit was obtained from BestBio (Shanghai, China).

Cell culture. DU145 human prostate cancer cells were obtained from the Affiliated Hospital of Qingdao University (Qingdao, China), and cultured in RPMI-1640 medium supplemented with $10 \%$ fetal bovine serum and antibiotics $(100 \mathrm{~g} / \mathrm{ml}$ streptomycin and $100 \mathrm{U} / \mathrm{ml}$ penicillin) at $37^{\circ} \mathrm{C}$ in an atmosphere of $5 \% \mathrm{CO}_{2}$.

Analysis of cell growth. DU145 cells were seeded into 96-well plates at a density of $1 \times 10^{4}$ cells/well and cultured with complete medium containing various concentrations of ursolic acid $(0,10,20,40$ and $80 \mu \mathrm{M})$ for 24,48 and $72 \mathrm{~h}$. Following ursolic acid treatment, CCK-8 reagent was added to the cells and incubated for $4 \mathrm{~h}$ at $37^{\circ} \mathrm{C}$ in an atmosphere of $5 \% \mathrm{CO}_{2}$. Subsequently, the absorbance of each well was detected at $450 \mathrm{~nm}$ using a microplate reader (Bio-Rad Laboratories, Inc., Hercules, CA, USA).

Flow cytometric analysis for cell apoptosis. DU145 cells were seeded into 6-well plates at a density of $1-2 \times 10^{6}$ cells/well and cultured with complete medium containing various concentrations of ursolic acid $(0,10,20$ and $40 \mu \mathrm{M})$ for $48 \mathrm{~h}$. DU145 cells were washed with cold phosphate-buffered saline twice and resuspended using $500 \mu \mathrm{l}$ of binding buffer. Following resuspension, $5 \mu \mathrm{l}$ of Annexin V-FITC and $10 \mu \mathrm{l}$ of PI were added and incubated for $10 \mathrm{~min}$ at $4^{\circ} \mathrm{C}$ in the dark. Flow cytometry

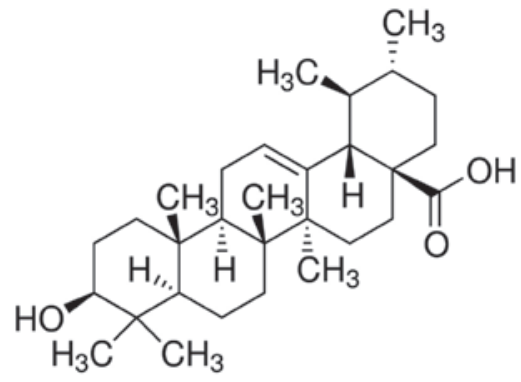

Figure 1. Chemical structure of ursolic acid.

was performed using a FACSCalibur flow cytometer (BD Biosciences, Franklin Lakes, NJ, USA).

Analysis of caspase-3 and caspase-9 activity. DU145 cells were seeded into 6-well plates at a density of $1-2 \times 10^{6}$ cells/well and cultured with complete medium containing various concentrations of ursolic acid $(0,10,20$ and $40 \mu \mathrm{M})$ for $48 \mathrm{~h}$. Cells were collected and the total protein concentration was determined using the bicinchoninic acid protein assay. Proteins were blended with $100 \mu \mathrm{l}$ of Caspase-Glo 3 or Caspase-Glo 9 reagent (Promega Corporation, Madison, WI, USA) and incubated for $2 \mathrm{~h}$ at room temperature. Luciferase activity was measured using a TD 20/20 luminometer (Promega Corporation).

Western blot analysis. DU145 cells were seeded into 6-well plates at a density of $1-2 \times 10^{6}$ cells/well and cultured with complete medium containing various concentrations of ursolic acid $(0,10,20$ and $40 \mu \mathrm{M})$ for $48 \mathrm{~h}$. DU145 cells were prepared using a ProteoJET cytoplasmic protein extraction kit (Fermentas; Thermo Fisher Scientific, Inc.) or a Mitochondrial Fractionation kit (Active Motif, Shanghai, China). The mixed liquor was collected to determine the total protein concentration using the bicinchoninic acid protein assay. Protein $(50 \mu \mathrm{g})$ was loaded onto 10-12\% SDS-PAGE gels for electrophoresis, transferred onto polyvinylidene difluoride (PVDF) membranes $(0.22 \mathrm{~mm})$ and blocked with Tris-buffered saline containing 5\% non-fat milk for $2 \mathrm{~h}$ at room temperature. Subsequently, PVDF membranes were incubated with primary antibodies against the following: Cytochrome $c$ (dilution, 1:2,000; \#BBA2469; BestBio), ROCK (dilution, 1:1,000; \#BBA5547; BestBio), PTEN (dilution, 1:1,000; \#BBA5274; BestBio) and cofilin-1 (dilution, 1:2,000; \#BBA2205; BestBio) overnight at $4^{\circ} \mathrm{C}$. PVDF membranes were subsequently incubated with horseradish peroxidase-conjugated sheep anti-mouse immunoglobulin $\mathrm{G}$ (dilution, 1:1,000; \#BB-2201-1; BestBio) at room temperature for $2 \mathrm{~h}$ and visualized by enhanced chemiluminescence. Protein expression was quantified using the ChemiDoc ${ }^{\mathrm{TM}}$ XRS system (Bio-Rad Laboratories, Inc.).

Statistical analysis. All data are expressed as the mean \pm standard deviation. Analysis of variance was performed followed by the Student-Newman-Keuls method for pairwise comparison. SPSS version 11.0 (SPSS, Inc., Chicago, IL, USA) was used to perform all statistical analyses. $\mathrm{P}<0.05$ was considered to indicate a statistically significant difference. 


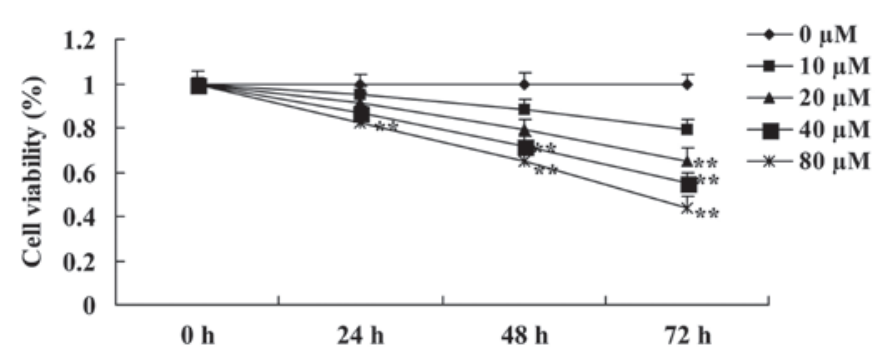

Figure 2. Anticancer effect of ursolic acid treatment on growth in prostate cancer cells. ${ }^{* *} \mathrm{P}<0.01$ compared with $0 \mu \mathrm{M}$ ursolic acid group.

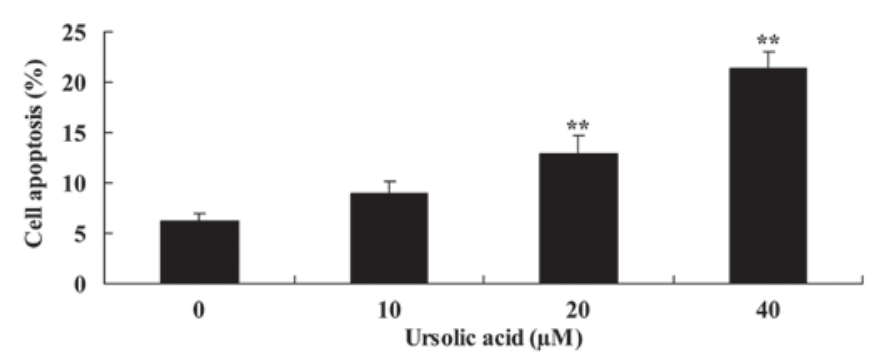

Figure 3. Anticancer effect of ursolic acid treatment on apoptosis in prostate cancer cells. ${ }^{* *} \mathrm{P}<0.01$ compared with $0 \mu \mathrm{M}$ ursolic acid group.

\section{Results}

Anticancer effect of ursolic acid treatment on cell growth in prostate cancer cells. Initially, the present study investigated the anticancer effect of ursolic acid treatment on the growth of DU145 cells. The results of the present study revealed the anticancer effect of ursolic acid treatment was able to reduce the growth of DU145 cells in a time- and dose-dependent manner (Fig. 2). Notably, when cells were treated with $20 \mu \mathrm{M}$ of ursolic acid for $72 \mathrm{~h}, 40 \mu \mathrm{M}$ of ursolic acid for 48 and $72 \mathrm{~h}$ or $80 \mu \mathrm{M}$ of ursolic acid for 24,48 and $72 \mathrm{~h}$, the growth of DU145 cells was significantly decreased compared with treatment with $0 \mu \mathrm{M}$ of ursolic acid (Fig. 2).

Anticancer effect of ursolic acid treatment on cell apoptosis in prostate cancer cells. Subsequently, the present study investigated the anticancer effect of ursolic acid treatment on apoptosis of DU145 cells. As shown in Fig. 3, treatment with ursolic acid (20 and $40 \mu \mathrm{M}$ ) significantly increased apoptosis of DU145 cells at $48 \mathrm{~h}$ in a dose-dependent manner, compared with treatment with $0 \mu \mathrm{M}$ of ursolic acid (Fig. 3).

Anticancer effect of ursolic acid treatment on caspase-3 and caspase-9 activity in prostate cancer cells. Subsequently, the present study investigated the anticancer effect of ursolic acid treatment on caspase- 3 and caspase- 9 activity of DU145 cells. Compared with treatment with $0 \mu \mathrm{M}$ of ursolic acid, treatment with ursolic acid (20 and $40 \mu \mathrm{M})$ significantly induced caspase- 3 and caspase- 9 activity of DU145 cells at $48 \mathrm{~h}$ in a dose-dependent manner (Fig. 4).

Anticancer effect of ursolic acid treatment on cytochrome $c$ protein expression in prostate cancer cells. To investigate the underlying anticancer mechanism of ursolic acid on prostate cancer cells, cytochrome $c$ protein expression in the cytoplasm
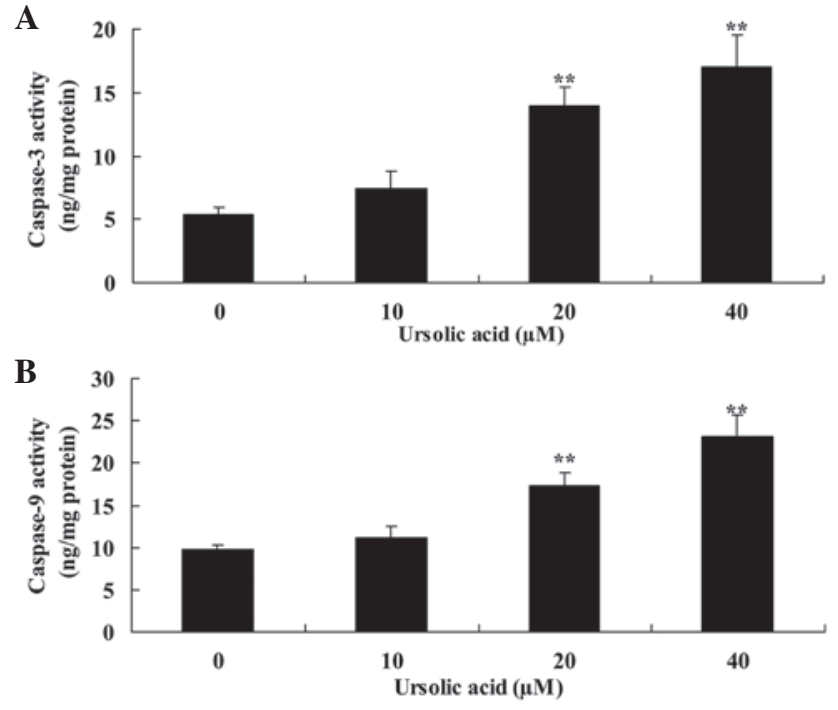

Figure 4. Anticancer effect of ursolic acid treatment on (A) caspase- 3 and (B) caspase-9 activity in prostate cancer cells. ${ }^{* *} \mathrm{P}<0.01$ compared with $0 \mu \mathrm{M}$ ursolic acid group.

$\mathbf{A}$

Cyt-Cytochrome c

Mit-Cytochrome c

$\beta$-actin

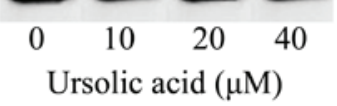

B

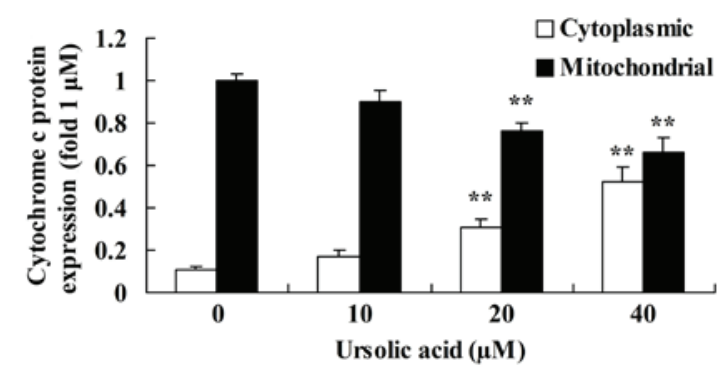

Figure 5. Anticancer effect of ursolic acid treatment on cytochrome $c$ protein expression in prostate cancer cells. Anticancer effect of ursolic acid treatment on cytochrome $c$ protein expression assessed (A) by western blotting assays and (B) quantification of cytochrome $c$ protein expression in prostate cancer cells. ${ }^{* *} \mathrm{P}<0.01$ compared with $0 \mu \mathrm{M}$ ursolic acid group.

and mitochondria was measured using western blotting. The results of the present study indicated that treatment with $\geq 20 \mu \mathrm{M}$ ursolic acid for $48 \mathrm{~h}$ significantly activated cytochrome $c$ protein expression in the cytoplasm of DU145 cells and suppressed cytochrome $c$ protein expression in the mitochondria of DU145 cells, compared with treatment with $0 \mu \mathrm{M}$ of ursolic acid (Fig. 5).

Anticancer effect of ursolic acid treatment on ROCK protein expression in prostate cancer cells. To observe the underlying mechanism of ursolic acid action on prostate cancer cells, ROCK protein expression was measured using western blotting. The results of the present study revealed that treatment with 20 and $40 \mu \mathrm{M}$ ursolic acid for $48 \mathrm{~h}$ significantly suppressed 
A

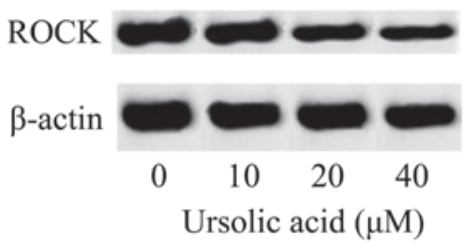

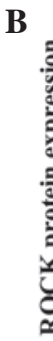

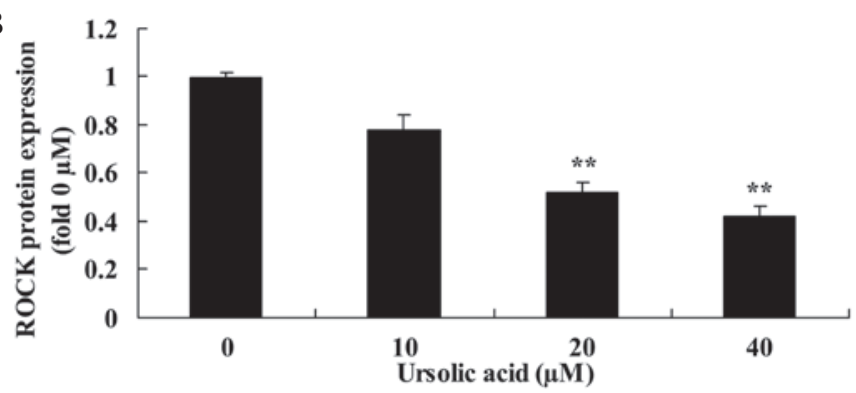

Figure 6. Anticancer effect of ursolic acid treatment on ROCK protein expression in prostate cancer. Anticancer effect of ursolic acid treatment on ROCK protein expression assessed (A) by western blotting assays and (B) quantification of ROCK protein expression in prostate cancer cells. ${ }^{* *} \mathrm{P}<0.01$ compared with $0 \mu \mathrm{M}$ ursolic acid group. ROCK, rho-associated protein kinase.
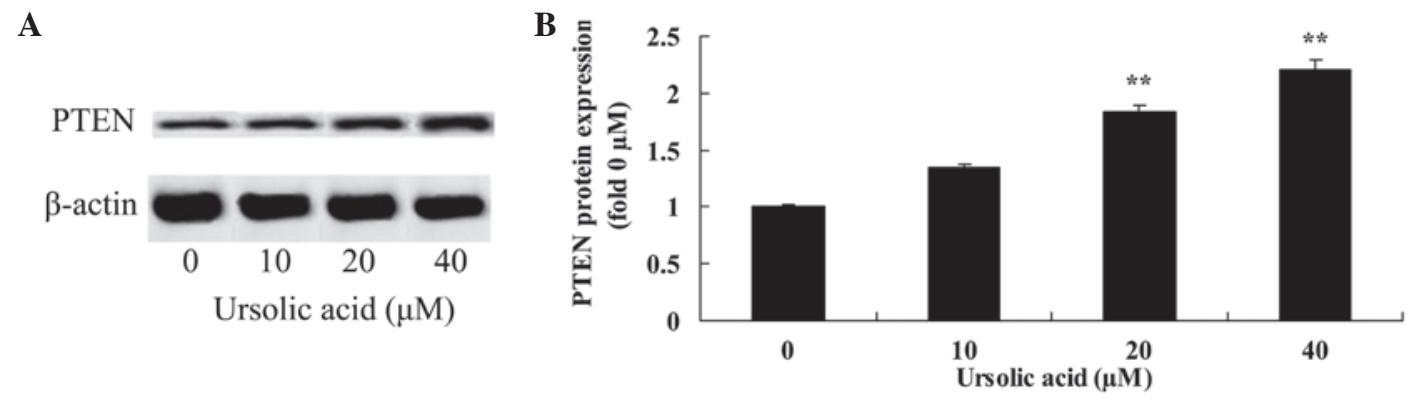

Figure 7. Anticancer effect of ursolic acid treatment on PTEN protein expression in prostate cancer. Anticancer effect of ursolic acid treatment on PTEN protein expression assessed (A) by western blotting assays and (B) quantification of PTEN protein expression in prostate cancer cells. ${ }^{* * *} \mathrm{P}<0.01$ compared with $0 \mu \mathrm{M}$ ursolic acid group. PTEN, phosphatase and tensin homolog.

A

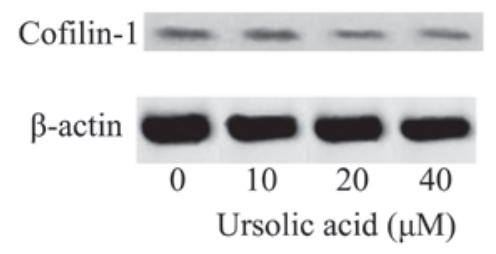

B

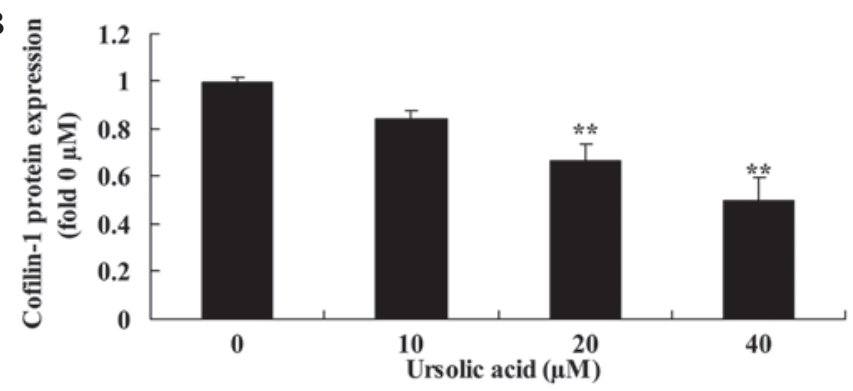

Figure 8. Anticancer effect of ursolic acid treatment on cofilin-1 protein expression in prostate cancer. Anticancer effect of ursolic acid treatment on cofilin-1 protein expression assessed (A) by western blotting assays and (B) quantification of cofilin-1 protein expression in prostate cancer cells. ${ }^{* *} \mathrm{P}<0.01$ compared with $0 \mu \mathrm{M}$ ursolic acid group.

ROCK protein expression in DU145 cells, compared with treatment with $0 \mu \mathrm{M}$ of ursolic acid (Fig. 6).

Anticancer effect of ursolic acid treatment on PTEN protein expression in prostate cancer cells. To investigate the underlying mechanism of ursolic acid action on prostate cancer cells, PTEN protein expression was measured using western blotting. Following $48 \mathrm{~h}$ of ursolic acid $(20$ and $40 \mu \mathrm{M})$ treatment, PTEN protein expression was significantly enhanced in DU145 cells, compared with treatment with $0 \mu \mathrm{M}$ of ursolic acid (Fig. 7).

Anticancer effect of ursolic acid treatment on cofilin-1 protein expression in prostate cancer cells. To investigate the underlying mechanism of ursolic acid action on prostate cancer cells, cofilin-1 protein expression was measured using western blotting. The results of the present study demonstrated that treatment with ursolic acid (20 and $40 \mu \mathrm{M})$ significantly reduced cofilin-1 protein expression in DU145 cells, compared with treatment with $0 \mu \mathrm{M}$ of ursolic acid (Fig. 8).

\section{Discussion}

Prostate carcinoma is common among elderly men and its morbidity in European and American developed countries is high, with up to 650,000 new cases each year (1). In 2008, there were 900,000 new cases of prostate carcinoma globally; therefore, prostate cancer has become the second most serious cancer in terms of its threat to men's health (21). The morbidity of prostate cancer is lower in East Asia; however, due to the aging population, dietary structure alterations and improvements in diagnosis, the morbidity is also rising in countries 
in this region (2). The present study observed that ursolic acid significantly suppressed cell growth, and induced apoptosis and caspase- 3 and caspase-9 activity in DU145 cells. Previous studies have revealed that ursolic acid is able to suppress cell proliferation and induce apoptosis of APC-mutated colon cancer cells (22), U937 cells (23) and colon cancer-initiating cells (24).

A current focus of cancer research concerns the development of medicines to promote cell apoptosis. Cytochrome $c$ is an essential component of the respiratory chain and has a significant role in the oxidation and reduction of cells (25). Utilized as a cell respiration-activating enzyme in the clinic, cytochrome $c$ is an ancillary drug used to treat cancer (26). Furthermore, cytochrome $c$ additionally has a significant role in apoptosis (27). A previous study reported the extraction of 3 substances associated with cell apoptosis, including cytochrome $c$ (28). It was observed that cells in adrenal cortex tumors of mice underwent apoptosis following treatment with cytochrome $c$ (27). In the present study, ursolic acid significantly activated cytochrome $c$ protein expression in the cytoplasm and suppressed cytochrome $c$ protein expression in mitochondria of DU145 cells. Achiwa et al (29) suggested that ursolic acid induces apoptosis in SNG-II endometrial cancer cells through reduction of mitochondrial cytochrome $c$ release. Li et al (25) reported that ursolic acid induced apoptosis of SGC-7901 gastric cancer cells through cytochrome $c$.

Prostate carcinoma cells may express RhoA protein, and the expression of RhoA protein in prostate carcinoma is higher than that in benign prostatic hyperplasia (BPH) (30). Therefore it has been speculated that the formation of prostate carcinoma may be associated with overexpression of RhoA $(30,31)$. The present study observed that prostate cells expressed ROCK/PTEN protein, and the expression of ROCK/PTEN protein in prostate carcinoma is also higher than that in $\mathrm{BPH}$. Furthermore, the expression level of RhoA and ROCK/PTEN protein demonstrates significant positive correlation $(30,31)$. These findings indicated that the ROCK/PTEN signal transduction pathway may participate in the occurrence of prostate carcinoma, and the expression level of ROCK/PTEN protein may be regulated and controlled by RhoA (32). The present study observed that ursolic acid significantly downregulated the ROCK/PTEN signal transduction pathway in DU145 cells. Li et al (25) reported that ursolic acid induced apoptosis of SGC-7901 gastric cancer cells through suppression of ROCK/PTEN.

Cofilin-1 is a eukaryotic actin-binding protein with a low molecular mass. The cofilin-1 gene is located at llq13 (32). In addition, cofilin- 1 has a large amount of biological activities, including participating in cell apoptosis, cytoplasmic division and affecting phalloidin (33). It has been reported that cofilin-1 protein will translocate into the mitochondria from the cytoplasm; subsequently, cytochrome $c$ will be released from mitochondria and combine with Apaf-1 to activate caspase-9, so that the caspase cascade will be activated and lead to apoptosis (19). In addition, the corresponding mechanism of action of cofilin-1 may be associated with the promotion of cyclase-associated protein 1 (25). Furthermore, when cofilin-1 protein translocates into the mitochondria from the cytoplasm, it activates cytochrome $c$ release and activation of the caspase cascade, indirectly inducing cell apoptosis (25). The results of the present study demonstrated that ursolic acid significantly inhibited cofilin-1 protein expression in DU145 cells. Previous studies have reported that ursolic acid induces apoptosis of SGC-7901 and BGC-823 gastric cancer cells through suppression of mitochondrial translocation of cofilin-1 $(25,34)$.

In conclusion, the results of the present study suggest that ursolic acid suppresses cell growth, induces apoptosis and increases caspase- 3 and caspase-9 activity in DU145 cells. Ursolic acid treatment affects cytochrome $c$ protein expression in the cytoplasm and mitochondria, leading to suppression of ROCK/PTEN signaling and mitochondrial translocation of cofilin-1 in prostate cancer cells. Therefore, ursolic acid may present a novel treatment strategy for prostate cancer by targeting ROCK/PTEN and mitochondrial translocation of cofilin-1, leading to activation of apoptosis.

\section{References}

1. Dossus L, Kaaks R, Canzian F, Albanes D, Berndt SI, Boeing H, Buring J, Chanock SJ, Clavel-Chapelon F, Feigelson HS, et al: PTGS2 and IL6 genetic variation and risk of breast and prostate cancer: Results from the Breast and Prostate Cancer Cohort Consortium (BPC3). Carcinogenesis 31: 455-461, 2010.

2. Jiang J, Yu L, Huang X, Chen X, Li D, Zhang Y, Tang L and Zhao S: Identification of two novel human dynein light chain genes, DNLC2A and DNLC2B, and their expression changes in hepatocellular carcinoma tissues from 68 Chinese patients. Gene 281: 103-113, 2001.

3. Che JP, Li W, Yan Y, Liu M, Wang GC, Li QY, Yang B, Yao XD and Zheng JH: Expression and clinical significance of the nin one binding protein and p38 MAPK in prostate carcinoma. Int $\mathbf{J}$ Clin Exp Pathol 6: 2300-2311, 2013.

4. Gao L, Wang XD, Niu YY, Duan DD, Yang X, Hao J, Zhu CH, Chen D, Wang KX, Qin XM and Wu XZ: Molecular targets of Chinese herbs: A clinical study of hepatoma based on network pharmacology. Sci Rep 6: 24944, 2016.

5. Yen HR, Chen YY, Huang TP, Chang TT, Tsao JY, Chen BC and Sun MF: Prescription patterns of Chinese herbal products for patients with uterine fibroid in Taiwan: A nationwide population-based study. J Ethnopharmacol 171: 223-230, 2015.

6. Su M, Wu X, Chung HY, Li Y and Ye W: Antiproliferative activities of five Chinese medicinal herbs and active compounds in Elephantopus scaber. Nat Prod Commun 4: 1025-1030, 2009.

7. Hsieh TC, Lu X, Guo J, Xiong W, Kunicki J, Darzynkiewicz Z and $\mathrm{Wu}$ JM: Effects of herbal preparation Equiguard on hormone-responsive and hormone-refractory prostate carcinoma cells: Mechanistic studies. Int J Oncol 20: 681-689, 2002.

8. Gui Y, Qiu X, Xu Y, Li D and Wang L: Bu-Shen-Ning-Xin decoction suppresses osteoclastogenesis via increasing dehydroepiandrosterone to prevent postmenopausal osteoporosis. Biosci Trends 9: 169-181, 2015

9. Jenny M, Wondrak A, Zvetkova E, Nguyen Thi Ngoc Tram,4 Phi Phi PT, Schennach H, Culig Z Ueberall F and Fuchs1 D: Crinum Latifolium leave extracts suppress immune activation cascades in peripheral blood mononuclear cells and proliferation of prostate tumor cells. Sci Pharm 79: 323-335, 2011.

10. Lin YH, Chen KK and Chiu JH: Prevalence, patterns and costs of Chinese medicine use among prostate cancer patients: A population-based study in Taiwan. Integr Cancer Ther 9: 16-23, 2010.

11. Zhang WB, Wang GJ and Fuxe K: Classic and modern meridian studies: A review of low hydraulic resistance channels along meridians and their relevance for therapeutic effects in Traditional Chinese Medicine. Evid Based Complement Alternat Med 2015: 410979, 2015.

12. Li N, Ma Z, Li M, Xing Y and Hou Y: Natural potential therapeutic agents of neurodegenerative diseases from the traditional herbal medicine Chinese dragon's blood. J Ethnopharmacol 152: 508-521, 2014.

13. Chen J, Wong HS and Ko KM: Ursolic acid-enriched herba cynomorii extract induces mitochondrial uncoupling and glutathione redox cycling through mitochondrial reactive oxygen species generation: Protection against menadione cytotoxicity in h9c2 cells. Molecules 19: 1576-1591, 2014. 
14. Liao Q, Yang W, Jia Y, Chen X, Gao Q and Bi K: LC-MS determination and pharmacokinetic studies of ursolic acid in rat plasma after administration of the traditional chinese medicinal preparation Lu-Ying extract. Yakugaku Zasshi 125: 509-515, 2005.

15. Gao N, Cheng S, Budhraja A, Gao Z, Chen J, Liu EH, Huang C, Chen D, Yang Z, Liu Q, et al: Ursolic acid induces apoptosis in human leukaemia cells and exhibits anti-leukaemic activity in nude mice through the PKB pathway. Br J Pharmacol 165: 1813-1826, 2012.

16. Yie Y, Zhao S, Tang Q, Zheng F, Wu J, Yang L, Deng S and Hann SS: Ursolic acid inhibited growth of hepatocellular carcinoma HepG2 cells through AMPKo-mediated reduction of DNA methyltransferase 1. Mol Cell Biochem 402: 63-74, 2015.

17. Huang L, Chen T, Ye Z and Chen G: Use of liquid chromatography-atmospheric pressure chemical ionization-ion trap mass spectrometry for identification of oleanolic acid and ursolic acid in Anoectochilus roxburghii (wall.) Lindl. J Mass Spectrom 42: 910-917, 2007.

18. Chang CY, Leu JD and Lee YJ: The actin depolymerizing factor $(\mathrm{ADF}) /$ cofilin signaling pathway and DNA damage responses in cancer. Int J Mol Sci 16: 4095-4120, 2015.

19. Li GB, Cheng Q, Liu L, Zhou T, Shan CY, Hu XY, Zhou J, Liu EH, Li P and Gao N: Mitochondrial translocation of cofilin is required for allyl isothiocyanate-mediated cell death via ROCK1/PTEN/PI3K signaling pathway. Cell Commun Signal 11: 50, 2013.

20. Vitolo MI, Boggs AE, Whipple RA, Yoon JR, Thompson K, Matrone MA, Cho EH, Balzer EM and Martin SS: Loss of PTEN induces microtentacles through PI3K-independent activation of cofilin. Oncogene 32: 2200-2210, 2013.

21. Klotz L, Boccon-Gibod L, Shore ND, Andreou C, Persson BE, Cantor P, Jensen JK, Olesen TK and Schröder FH: The efficacy and safety of degarelix: A 12-month, comparative, randomized open-label, parallel-group phase III study in patients with prostate cancer. BJU Int 102: 1531-1538, 2008.

22. Kim JH, Kim YH, Song GY, Kim DE, Jeong YJ, Liu KH, Chung $\mathrm{YH}$ and $\mathrm{Oh} \mathrm{S}$ : Ursolic acid and its natural derivative corosolic acid suppress the proliferation of APC-mutated colon cancer cells through promotion of $\beta$-catenin degradation. Food Chem Toxicol 67: 87-95, 2014

23. Deng L, Zhang R, Tang F, Li C, Xing YY and Xi T: Ursolic acid induces U937 cells differentiation by PI3K/Akt pathway activation. Chin J Nat Med 12: 15-19, 2014.
24. Wang W, Zhao C, Jou D, Lü J, Zhang C, Lin L and Lin J: Ursolic acid inhibits the growth of colon cancer-initiating cells by targeting STAT3. Anticancer Res 33: 4279-4284, 2013.

25. Li R, Wang X, Zhang XH, Chen HH and Liu YD: Ursolic acid promotes apoptosis of SGC-7901 gastric cancer cells through ROCK/PTEN mediated mitochondrial translocation of cofilin-1. Asian Pac J Cancer Prev 15: 9593-9597, 2014.

26. Yang YZ, Fan TT, Gao F, Fu J and Liu Q: Exogenous cytochrome c inhibits the expression of transforming growth factor- $\beta 1$ in a mouse model of sepsis-induced myocardial dysfunction via the SMAD1/5/8 signaling pathway. Mol Med Rep 12: 2189-2196, 2015.

27. Faizi M, Salimi A, Rasoulzadeh M, Naserzadeh P and Pourahmad J: Schizophrenia induces oxidative stress and cytochrome $\mathrm{C}$ release in isolated rat brain mitochondria: A possible pathway for induction of apoptosis and neurodegeneration. Iran J Pharm Res 13 (Suppl): S93-S100, 2014.

28. Katoch B, Sebastian S, Sahdev S, Padh H, Hasnain SE and Begum R: Programmed cell death and its clinical implications. Indian J Exp Biol 40: 513-524, 2002.

29. Achiwa Y, Hasegawa K, Komiya T and Udagawa Y: Ursolic acid induces Bax-dependent apoptosis through the caspase-3 pathway in endometrial cancer SNG-II cells. Oncol Rep 13: 51-57, 2005.

30. Mikelis CM, Simaan M, Ando K, Fukuhara S, Sakurai A, Amornphimoltham P, Masedunskas A, Weigert R, Chavakis T, Adams RH, et al: RhoA and ROCK mediate histamine-induced vascular leakage and anaphylactic shock. Nat Commun 6: 6725, 2015.

31. Li G, Liu L, Shan C, Cheng Q, Budhraja A, Zhou T, Cui H and Gao N: RhoA/ROCK/PTEN signaling is involved in AT-101-mediated apoptosis in human leukemia cells in vitro and in vivo. Cell Death Dis 5: e998, 2014.

32. Wang Y, Kuramitsu Y, Ueno T, Suzuki N, Yoshino S, Iizuka N, Zhang X, Oka M and Nakamura K: Differential expression of up-regulated cofilin-1 and down-regulated cofilin-2 characteristic of pancreatic cancer tissues. Oncol Rep 26: 1595-1599, 2011.

33. Yan H, Yang K, Xiao H, Zou YJ, Zhang WB and Liu HY: Over-expression of cofilin-1 and phosphoglycerate kinase 1 in astrocytomas involved in pathogenesis of radioresistance. CNS Neurosci Ther 18: 729-736, 2012.

34. Tang Q, Ji Q, Tang Y, Chen T, Pan G, Hu S, Bao Y, Peng W and Yin P: Mitochondrial translocation of cofilin-1 promotes apoptosis of gastric cancer BGC-823 cells induced by ursolic acid. Tumour Biol 35: 2451-2459, 2014. 